\title{
The prevalent status and genetic diversity of porcine reproductive and respiratory syndrome virus in China: a molecular epidemiological perspective
}

\author{
Zhenhua Guo ${ }^{1 *+}$, Xin-xin Chen ${ }^{1+}$, Rui Li ${ }^{1}$, Songlin Qiao ${ }^{1}$ and Gaiping Zhang ${ }^{1,2,3}$
}

\begin{abstract}
Porcine reproductive and respiratory syndrome virus (PRRSV) has been epidemic more than 30 years in America and 20 years in China. It is still one of the most important causative agents to the worldwide swine industry. Here, we systematically analyzed the prevalence status of PRRSV in China by a molecular epidemiological perspective. Now both PRRSV-1 and PRRSV-2 are circulating and approximately more than $80 \%$ of pig farms are seropositive for PRRSV. For PRRSV-2, there are four lineages (lineage 1, lineage 3, lineage 5, lineage 8) circulating in the fields. Lineage 8 ( $\mathrm{CH}-1$ a-like) and lineage 5 (BJ-4-like) appeared almost at the same time during 1995-1996. Notably, BJ-4 shares 99.6\% and 99.8\% identity with VR2332 and RespPRRS MLV, respectively. It means that lineage 5 is likely to be imported from America. Now highly pathogenic PRRSV (HP-PRRSV) which was considered to be evolved from local diversity of lineage 8 strains is predominant with different variants. Lineage 3 appeared in 2010 which is mainly sporadic in south of China. Lineage 1, also known as NADC30-like strains in China, has been prevalent since 2013 and leads to PRRS pandemic again. For PRRSV-1, although sporadic at present, more than 9 provinces/regions have been reported. All the circulating strains belong to subtype I. It should be paid more attention since there are no vaccines available. Our analysis would help to deeply understand the prevalent status of PRRSV in China and provide useful information for prevention and control of porcine reproductive and respiratory syndrome (PRRS).
\end{abstract}

Keywords: Porcine reproductive and respiratory syndrome virus (PRRSV), Molecular epidemiology, PRRSV-1, PRRSV-2, Control strategies

\section{Background}

Porcine reproductive and respiratory syndrome (PRRS) is one of the most important economically diseases to the swine industry worldwide. It is estimated that the total economic losses caused by PRRS is about $\$ 664$ million annually in the America, an increase from the $\$ 560$ million annual cost estimated in 2005 [1]. PRRS was firstly described in America in 1987 [2], followed in Europe and Asia (1990-1992) [3-6]. The causative agent, porcine reproductive and respiratory syndrome virus (PRRSV), was

\footnotetext{
* Correspondence: gzhuavet@163.com

${ }^{\dagger}$ Equal contributors

${ }^{1}$ Key Laboratory of Animal Immunology of the Ministry of Agriculture, Henan Provincial Key Laboratory of Animal Immunology, Henan Academy of Agricultural Sciences, Zhengzhou 450002, People's Republic of China

Full list of author information is available at the end of the article
}

isolated in 1991 in the Netherlands and 1992 in the United States with originally isolated strains named Lelystad Virus (the European prototypic strain) and Swine Infertility and Respiratory Syndrome (SIRS) virus (also known as ATCC VR-2332, the North American prototypic strain), respectively $[7,8]$. The retrospective studies showed that the conserved serum samples were PRRSV antibody positive as early as 1979 in Canada [9]. It suggested that PRRSV had already circulated in swine population before 1979 .

PRRSV is an enveloped, single positive-stranded RNA virus. It belongs to the family Arteriviridae of the order Nidovirales along with equine arteritis virus, lactate dehydrogenase-elevating virus and simian hemorrhagic fever virus [10]. Its genome size is about $15.4 \mathrm{~kb}$, which contains at least 10 open reading frames (ORFs) flanked by two untranslated regions $5^{\prime}$ 
and 3' (5'UTR-ORF1a-ORF1b-ORF2a-ORF2b-ORF3ORF4-ORF5/ORF5a-ORF6-ORF7-3'UTR). ORF1a and ORF1b encode two large polypeptides which produce 14 non-structural proteins by the viral enzymatic cleavage. ORF2 through ORF7 code eight structural proteins including GP2, E, GP3, GP4, GP5a, GP5, M and N [11-14]. Among them, ORF5 (gp5) is usually used for phylogenetic analyses because of its high variability. There are two genotypes of PRRSV: PRRSV-1 (European type) and PRRSV-2 (North American type) [15, 16]. Although these two types of PRRSV cause similar clinical disease to the infected pigs, they share only $55-70 \%$ nucleotide and $50-80 \%$ amino acid similarity in their various genes [17].

High genetic diversity is a significant characteristic of PPRSV. Mang Shi et al. constructed the global classification system of PRRSV based on the comprehensive analysis of the complete ORF5 gene sequence. According to the classification system, the PRRSV-1 was divided into three subtypes (subtype 1-3) and the PRRSV-2 was classified as 9 lineages with several sublineages of each lineage $[18,19]$. The virulence and antigenicity are also different and variable due to the genetic diversity. There are several highly pathogenic PRRSV (HP-PRRSV) strains which cause severe reproductive and/or respiratory diseases and the emergence of new HP-PRRSV often leads to the widespread re-pandemic of PRRS. For example, although the vaccine was used in the late 1990s, the "abortion storm" swept through the America and an atypical PRRSV strain MN184 was isolated in 2001 [20, 21]. In Eastern Europe, a highly pathogenic PRRSV, Lena strain, was reported by Belarus in 2010 [22]. In China, the emergence of HPPRRSV variants in 2006 led to atypical PRRS pandemics and $20 \%$ mortality in pigs [23]. Since 2013, PRRS became prevalent again in China caused by new PRRSV variants, NADC30-like strains, which are considered to be imported from North American and adapted in China [24, 25].

Here, we retrospectively and phylogenetically analyzed the prevalence and genetic diversity of PRRSV in China through a molecular epidemiological perspective. We hope to provide valuable information and new insights for the PRRSV epidemic trends and control strategies. Genome analyses were performed using the DNASTAR package. The unrooted phylogenetic tree was generated by the distance-based neighbor-joining method using MEGA 6.0 and the amino acid sequences were aligned by Clustal W method (MEGA 6.0) [26]. The recombination events were detected by RDP4 program using seven different algorithms (RDP, GeneConv, BootScan, MaxChi, Chimera, SiScanm and 3Seq) with Bonferroni correction and a highest acceptable $p$-value of 0.01 [27].

\section{PRRSV history and prevalent status in China}

PRRS was firstly described in 1995 in China and the etiological agent, PRRSV, was isolated by Guo et al. (1996) and Yang et al. (1997). The isolated strains were named CH-1a (Genbank ID: AY032626) and BJ-4 (Genbank ID: AF331831), respectively. Both of them belong to PRRSV-2 $[28,29]$. Serological studies showed that the percent of positive serum is more than $40 \%$ in the east and north of China [30], and it means that PRRSV circulated in China earlier than 1995. It is not clear how the PRRSV was introduced into pig population in China. One possibility is the import of breeding pigs. The evidences are: (i) Chen et al. (1996) successfully isolated PRRSV strain from the imported breeding pigs from Canada [31]; (ii) The genome homology of BJ-4 with VR2332 is about $99.6 \%$ and the genome homology of $\mathrm{CH}-1 \mathrm{a}$ with JA142 (Genbank ID: AY424271) is about $94.5 \%$. Both of them (especially BJ-4) are closely related to North American isolates and PRRSV was endemic during 1995 2005.

During the summer of 2006, a new PRRSV variant, also known as highly pathogenic PRRSV (HP-PRRSV), caused atypical PRRS and led to a devastating destruction to swine industry with $20 \%$ motality to pigs. The new PRRSV variants show a unique discontinuous 30 amino acids (482aa, 534-562aa) deletion in Nsp2 gene [22]. The representative virus strains are JXA1 (Genbank ID: EF112445), TJ (Genbank ID: EU860248) and HuN4 (Genbank ID: EF635006) which are also the parent strains for attenuated vaccine strains JXA1-R, TJM-F92 and HuN4-F112, respectively [32-34]. The HP-PRRSVlike strains are predominantly epidemic strains in the pig farms after 2006. Since 2013, there was a markedly increased PRRSV infection during routinely clinical investigation. The reason for this re-pandemic of PRRS is considered as the emergence of NADC30-like strains which were probably imported from North America and went though extensive variation in China [24, 25, 35]. Now both HP-PRRSV-like and NADC30-like strains are mainly circulating in the fields and have a high clinical detection rate.

For the PRRSV-1, B13 (Genbank ID: AY633973) was the earliest strain reported in China. It was conserved in Dalian Animal and Plant Quarantine Bureau, whose original source is not clear [36]. The retrospective studies showed that the PRRSV-1 strains could be detected from clinical samples as early as 2006 in mainland of China [37]. And now they are sporadic in more than nine provinces/regions (Inner Mongolia, Heilongjiang, Liaoning, Beijing, Fujian, Guizhou, Guangdong, Shanghai, Hong Kong) [38]. We should pay more attention to the prevalence of European type in China since more and more clinical investigation reported their existence and there are no authorised vaccines yet.

\section{The epidemic of PRRSV-2 in China}

Based on the global PRRSV classification system and ORF5 sequence information in the Genbank, we chose 
127 PRRSV-2 ORF5 sequences, including 9 reference strains and 118 prevalent strains (Table 1). As shown in Fig. 1, the prevalent PRRSV-2 strains in China were clustered into four lineages: lineage 1 , lineage 3 , lineage 5 (sublineage 5.1) and lineage 8 (sublineage 8.7). Lineage 8 is predominant since the emergence of PRRSV in China which included classical PRRSV strains (CH-1a-like) prevalent before 2006 and HP-PRRSV-like strains prevalent after 2006. The epidemic of lineage 1, also known as NADC30-like strains, which spread rapidly around the country since 2013 and now the clinical detection rate is comparable with lineage 8 (HP-PRRSV-like). Lineage 3 was another newly emerged variants since 2010 which is mainly circulating in south of China (Jiangxi, Fujian, Guangdong, Guangxi) and the clinical detection rate is less than $10 \%[39,40]$. Although the lineage 5 (BJ-4-like/ VR2332-like) appeared as early as in 1996, it is always non-pandemic in China and the clinical detection rate is low. It is still a puzzle that how the lineage 8 (HPPRRSV-like) and lineage 1 (NADC30-like) become the major epidemic strains, while lineage 8 ( $\mathrm{CH}$-1a-like) and lineage 5 are always endemic in China. One reasonable explain is that HP-PRRSV-like and NADC30-like strains show high genetic variations and incidence of recombination, compared with lineage 8 (CH-1a-like) and lineage 5 . These characteristics probably made current vaccines ineffective and confer them much easier to escape the immune surveillance. Thus, they adapted well during the pig populations.

\section{Lineage $8 /$ sublineage 8.7}

According to the phylogenetic assay of ORF5 sequence, sublineage 8.7 could be divided into five subgroupssubgroup I subgroup V (Fig. 1). Subgroup I is PRRSV strains that are closely related with $\mathrm{CH}-1 \mathrm{a}$. $\mathrm{CH}-1 \mathrm{a}$ was the first isolated PRRSV strain in China and was recognized as an ancestor strain of classical PRRSV. The genome homology is $94.5 \%$ with JA142 (Genbank ID: AY424271) and SDSU73 (Genbank ID: JN654458) (sublineage 8.9 ) and $91.5 \%$ with VR2332 (sublineage 5.1). Subgroup II was considered as intermediate subgroup between classical and HP-PRRSV. BJ0706 (Genbank ID: GQ351601) and NB-04 (Genbank ID: FJ536165) were the representative strains of transition [41]. They have been found 1aa deletion at the 481th residue site in Nsp2 gene and they showed a genome identity of 95.1 95.8\% with $\mathrm{CH}-1 \mathrm{a}$ and $97.1 \sim 98 \%$ with JXA1. Subgroup III V belong to HP-PRRSV derivative strains or HP-PRRSV vaccine derivative strains. HP-PRRSV leaded to the outbreak of PRRS in China in 2006. The representative strains JXA1, TJ, HuN4 show 95.3\% of genome homology with $\mathrm{CH}-1 \mathrm{a}$ and $89.6 \%$ with BJ-4. At present more consistent view is that HP-PRRSV is originated from lineage8 strains that have been circulating in China for about 10 years before the outbreak in 2006 [19]. The genetic diversity is still expanding and shows different evolutionary clusters following circulation of HP-PRRSV and extensive vaccination of modified live vaccines (JXA1-R, TJM-F92, HuN4-F112). Subgroup III is genetically closer with JXA1, also called JXA1-like group. Subgroup IV is evolutionarily close to TJ and HuN4 strains. Subgroup V is closely related with HP-PRRSV attenuated live vaccines. Considering modified live vaccines could circulate in the fields, it is expected to see many vaccines related sequences. And this also pose a challenge for a rapidly accurate diagnosis and control of PRRS.

\section{Lineage $\mathbf{5}$ /sublineage 5.1 and lineage 3}

Sublineage 5.1 appeared very early in China. The representative strain BJ-4 was isolated by Yang et al. in 1997 [29]. It shows $99.6 \%$ and $99.8 \%$ of genome homology with VR2332 and RespPRRS MLV (Boehringer Ingelheim, Germany), respectively. It suggests that sublineage 5.1 is more likely to be imported into China from North American. It is still not known why the prevalence of sublineage 5.1 is limited compared with lineage 8 . Lineage 3 was firstly reported in 2010 and considered as a novel lineage originally $[42,43]$. It is mainly endemic in southeast of China (Jiangxi, Fujian, Guangdong, Guangxi) [38]. The representative strains GM2 (Genbank ID: JN662424) and QYYZ (Genbank ID: JQ308798) show 86.2 88.7\% of genome homology with VR2332, CH-1a, BJ-4 and JXA1. Lineage 3 is genetically distant from previous epidemic strains and its source remains to be further clarified. Clinical detection rate of both sublineage 5.1 and lineage 3 is less than $10 \%$.

\section{Lineage 1}

Lineage 1, also known as NADC30-like strains, has been reported since 2013 in China [44]. Now it's epidemic in more than nine provinces/regions including northeast, southeast, central and east of China. The clinical detection rate is increasing every year and up to $50 \%$ in Henan Province [45]. The representative virus strain HENAN-XINX (Genbank ID: KF611905) and JL580 (Genbank ID: KR706343) share 86.7 87.8\% genome homology with MN184A (Genbank ID: DQ176019) isolated in 2001 in America, 92.8 95.4\% with NADC30 isolated in 2008 in America and 82.2 87.2\% with $\mathrm{CH}$ 1a, BJ-4, JXA1 and QYYZ. Like MN184A and NADC30, the NADC30-like virus strain in China shows the identical deletion pattern of nsp2 including 131aa discontinuous deletion. NADC30 is likely to be introduced into China by import of breeding pigs [24, 25, 35].

Compared with the other PRRSV lineages in China, NADC30-like strains show more recombination possibilities and pathogenic diversity (Table 2). There are several reports about the recombination of NADC30-like strains 
Table 1 The reference sequence information of PRRSV-2

\begin{tabular}{|c|c|c|c|c|c|c|c|}
\hline No. & Virus strain & Origin & Accession no. & No. & Virus strain & Origin & Accession no \\
\hline 1 & ATCC VR2332 & USA, 1992 & U87392 & 40 & HN2007 & China, 2008 & EU880437 \\
\hline 2 & RespPRRS MLV & USA, 1994 & AF066183 & 41 & SX2007 & China, 2008 & EU880434 \\
\hline 3 & SDSU73 & USA, 1996 & JN654458 & 42 & SD-CXA/2008 & China, 2008 & GQ359108 \\
\hline 4 & JA142 & USA, 1997 & AY424271 & 43 & XL2008 & China, 2008 & EU880436 \\
\hline 5 & Ingelvac ATP & USA, 1999 & DQ988080 & 44 & YN2008 & China, 2008 & EU880435 \\
\hline 6 & MN184A & USA, 2001 & DQ176019 & 45 & GS2008 & China, 2008 & EU880431 \\
\hline 7 & P129 & USA, 2002 & AF494042 & 46 & PRRSV01 & China, 2008 & FJ175687 \\
\hline 8 & NADC30 & USA, 2008 & JN654459 & 47 & KP & China, 2008 & GU232735 \\
\hline 9 & NADC31 & USA, 2008 & JN660150 & 48 & YN9 & China, 2008 & GU232738 \\
\hline 10 & $\mathrm{CH}-1 \mathrm{a}$ & China, 1996 & AY032626 & 49 & $\mathrm{JN}-\mathrm{HS}$ & China, 2008 & HM016158 \\
\hline 11 & $\mathrm{CH}-1 \mathrm{R}$ & China, 2008 & EU807840 & 50 & GDBY1 & China, 2008 & GQ374442 \\
\hline 12 & BJ-4 & China, 1996 & AF331831 & 51 & ZP-1 & China, 2009 & HM016159 \\
\hline 13 & S1 & China, 1999 & DQ459471 & 52 & SD1-100 & China, 2009 & GQ914997 \\
\hline 14 & SCQ & China, 2000 & DQ379479 & 53 & GS2002 & China, 2009 & EU880441 \\
\hline 15 & HB-1(sh)/2002 & China, 2001 & AY150312 & 54 & $\mathrm{CH} 2002$ & China, 2009 & EU880438 \\
\hline 16 & HB-2(sh)/2002 & China, 2001 & AY262352 & 55 & YD & China, 2009 & JF748717 \\
\hline 17 & $\mathrm{HB}-1 / 3.9 \mathrm{C}$ & China, 2002 & HQ233605 & 56 & $S X-1$ & China, 2009 & GQ857656 \\
\hline 18 & GS2003 & China, 2003 & EU880442 & 57 & SY0909 & China, 2009 & HQ315837 \\
\hline 19 & HN1 & China, 2003 & AY457635 & 58 & 09HEB & China, 2009 & JF268679 \\
\hline 20 & Henan2 & China, 2004 & AY613349 & 59 & 09HEN1 & China, 2009 & $J F 268684$ \\
\hline 21 & NB-04 & China, 2004 & FJ536165 & 60 & 09HUB1 & China, 2009 & JF268682 \\
\hline 22 & FJ04A & China, 2004 & DQ246451 & 61 & HN-0902 & China, 2009 & JX162590 \\
\hline 23 & $\mathrm{SHB}$ & China, 2005 & EU864232 & 62 & HN-09 & China, 2009 & JX174280 \\
\hline 24 & JXA1 & China, 2006 & EF112445 & 63 & SD0901 & China, 2009 & JN256115 \\
\hline 25 & JXA1-p80 & China, 2008 & FJ548853 & 64 & $D C$ & China, 2010 & JF748718 \\
\hline 26 & JXA1-P120 & China, 2009 & KC422727 & 65 & GX1003 & China, 2010 & JX912249 \\
\hline 27 & JXA1-P170 & China, 2009 & JQ804986 & 66 & QY2010 & China, 2010 & JQ743666 \\
\hline 28 & HuN4 & China, 2006 & EF635006 & 67 & 10-10HEB-3 & China, 2010 & JQ663553 \\
\hline 29 & TJ & China, 2006 & EU860248 & 68 & Shanxi-6 & China, 2010 & KJ855518 \\
\hline 30 & HEB1 & China, 2006 & EF112447 & 69 & GX1001 & China, 2010 & JQ955657 \\
\hline 31 & R98 & China, 2006 & DQ355796 & 70 & 10-FUJ-2 & China, 2010 & JQ663547 \\
\hline 32 & HUB1 & China, 2006 & EF075945 & 71 & 10-FUJ-1 & China, 2010 & JQ663546 \\
\hline 33 & BJ0706 & China, 2007 & GQ351601 & 72 & $J X$ & China, 2010 & JX317649 \\
\hline 34 & GD & China, 2007 & EU825724 & 73 & GM2 & China, 2011 & JN662424 \\
\hline 35 & WUH1 & China, 2007 & EU187484 & 74 & QYYZ & China, 2011 & JQ308798 \\
\hline 36 & Henan-1 & China, 2007 & EU200962 & 75 & GD-2011 & China, 2011 & KC527830 \\
\hline 37 & NM1 & China, 2007 & EU860249 & 76 & NJ-1106 & China, 2011 & JX880029 \\
\hline 38 & GDQJ & China, 2007 & GQ374441 & 77 & NVDC-JS2-2011 & China, 2011 & JQ715698 \\
\hline 39 & NT0801 & China, 2008 & HQ315836 & 78 & $\mathrm{HH} 08$ & China, 2011 & JX679179 \\
\hline 79 & SDA3 & China, 2011 & JX878380 & 104 & CHsx1401 & China, 2014 & KP861625 \\
\hline 80 & SDA2 & China, 2011 & JX878379 & 105 & 14LY01-FJ & China, 2014 & KP780881 \\
\hline 81 & WUH4 & China, 2011 & JQ326271 & 106 & 14LY02-FJ & China, 2014 & KP780882 \\
\hline 82 & YN-2011 & China, 2011 & JX857698 & 107 & TJbd14-1 & China, 2014 & KP742986 \\
\hline
\end{tabular}


Table 1 The reference sequence information of PRRSV-2 (Continued)

\begin{tabular}{|c|c|c|c|c|c|c|c|}
\hline No. & Virus strain & Origin & Accession no. & No. & Virus strain & Origin & Accession no. \\
\hline 83 & $\mathrm{HZ}-31$ & China, 2012 & KC445138 & 108 & HENZMD-1 & China, 2014 & KT424216 \\
\hline 84 & GX1002 & China, 2012 & JQ955658 & 109 & HENJZ-2 & China, 2014 & KT424217 \\
\hline 85 & SD16 & China, 2012 & JX087437 & 110 & HENZK-2 & China, 2014 & KT424218 \\
\hline 86 & 10-10J & China, 2012 & JQ663554 & 111 & GDsg & China, 2015 & KX621003 \\
\hline 87 & $J L-04 / 12$ & China, 2012 & JX177644 & 112 & FJXS15 & China, 2015 & KX758250 \\
\hline 88 & SD16 & China, 2012 & JX087437 & 113 & TJnh1501 & China, 2015 & KX510269 \\
\hline 89 & FJFS & China, 2012 & KP998476 & 114 & HNjZ15 & China, 2015 & KT945017 \\
\hline 90 & NT1 & China, 2012 & KP179402 & 115 & HNyc15 & China, 2015 & KT945018 \\
\hline 91 & MY-376 & China, 2013 & KJ609517 & 116 & JL580 & China, 2015 & KR706343 \\
\hline 92 & Henan-A4 & China, 2013 & KJ534539 & 117 & HLJ58 & China, 2015 & KR706344 \\
\hline 93 & HeNan-A1 & China, 2013 & KJ002451 & 118 & HENXC-4 & China, 2015 & KU950371 \\
\hline 94 & HENAN-HEB & China, 2013 & KF416334 & 119 & JXja15 & China, 2015 & KR149645 \\
\hline 95 & HENAN-XINX & China, 2013 & KF611905 & 120 & 15LY01-FJ & China, 2015 & KU215416 \\
\hline 96 & HLJA1 & China, 2013 & KT351739 & 121 & 15LY02-FJ & China, 2015 & KU215417 \\
\hline 97 & HENAN-LUOY & China, 2013 & KF416330 & 122 & FZ16A & China, 2016 & KY761966 \\
\hline 98 & FJZ03 & China, 2013 & KP860909 & 123 & HeNhx & China, 2016 & KX766379 \\
\hline 99 & FJW05 & China, 2013 & KP860911 & 124 & HeNws16 & China, 2016 & MF474322 \\
\hline 100 & FJ1402 & China, 2014 & KX169191 & 125 & HeNzm1-16 & China, 2016 & MF474323 \\
\hline 101 & HENJZ-2 & China, 2014 & KT424217 & 126 & HeNzm2-16 & China, 2016 & MF474324 \\
\hline 102 & HENPDS-1 & China, 2014 & KT424228 & 127 & HeNmz16 & China, 2016 & MF474321 \\
\hline 103 & FJ1405 & China, 2014 & KM453701 & & & & \\
\hline
\end{tabular}

including NADC30 with HP-PRRSV [24, 46-48], NADC30 with vaccine strain (TJM-like, JXA1-P80) [49-51] and with classical PRRSV (CH-1a, VR2332) [48, 52]. Besides, lineage 8 and lineage 3 also display different degrees of recombination $[53,54]$. For the virulence difference, some NADC30like strains (JL580, FJ1402 etc.) show high pathogenicity comparable with HP-PRRSV [24, 47, 51]. Some NADC30like strains (TJnh1501, HNjz15 etc.) display intermediate virulence similar to the prototype strain-NADC30 $[49,55]$. A reasonable explanation is that NADC30 underwent extensive mutations and recombination since it was introduced into China. Especially the exchange of gene fragment from different circulating strains which endow new biological characteristics to different variants, for example, the change of pathogenicity and antigenicity.

\section{The epidemic of PRRSV-1 in China}

Although there are more recent reports about the prevalence of European type PRRSV in China, the clinical detection rate is still low [37, 56-58]. Now the research mainly focuses on the molecular epidemiology of PRSSV-1 in China. Here we did a genetic diversity assay based on the ORF5 sequence by choosing 20 strains isolated in China and 23 reference strains (Table 3 ). The results showed all the Chinese isolated strains belong to subtype 1 (pan-European type) and could be further divided into four subgroups (Fig. 2). Our analysis may provide valuble information for the classification of future PRRSV-1 strains for other researchers.

\section{Genetic variation}

The genome homology between Chinese isolated strains and Lelystad virus ranges from $85.9 \%$ to $92.7 \%$, and the similarity of ORF5 with Lelystad virus is about $83.5 \sim 94.6 \%$ except the B13 which shows $99.7 \%$, only two nucleotides different from Lelystad virus. It suggests that B13 may be isolated from import breeding pigs or as a standard reference strain from some western European countries. Considering the close communication of pig breeding between China and Europe, it is not surprising to see the appearance of PRRSV-1 in China. As the phylogenetic tree showed, The Chinese PRRSV-1 isolations are further clustered into four subgroups. Subgroup I was closely related with Amervac PRRSV virus, a live vaccine virus of PRRSV-1 and SHE, a rescued virus from an infectious clone of Amervac PRRS virus. Subgroup II was mainly limited in HongKong and it is geographically restrictive. Subgroup III is NMEU09-1/2-like isolates and subgroup IV is BJEU06-1-like strains. According to the amino acid alignment of ORF5 (Fig. 3), the 8/60/63/106 sites were highly variable which have 3 to 7 different amino acid mutations. The $37\left(\mathrm{~N} / \mathrm{D}^{\mathrm{LV}}\right), 100\left(\mathrm{~V} / \mathrm{T}^{\mathrm{LV}}\right), 101\left(\mathrm{~T} / \mathrm{A}^{\mathrm{LV}}\right), 112$ 


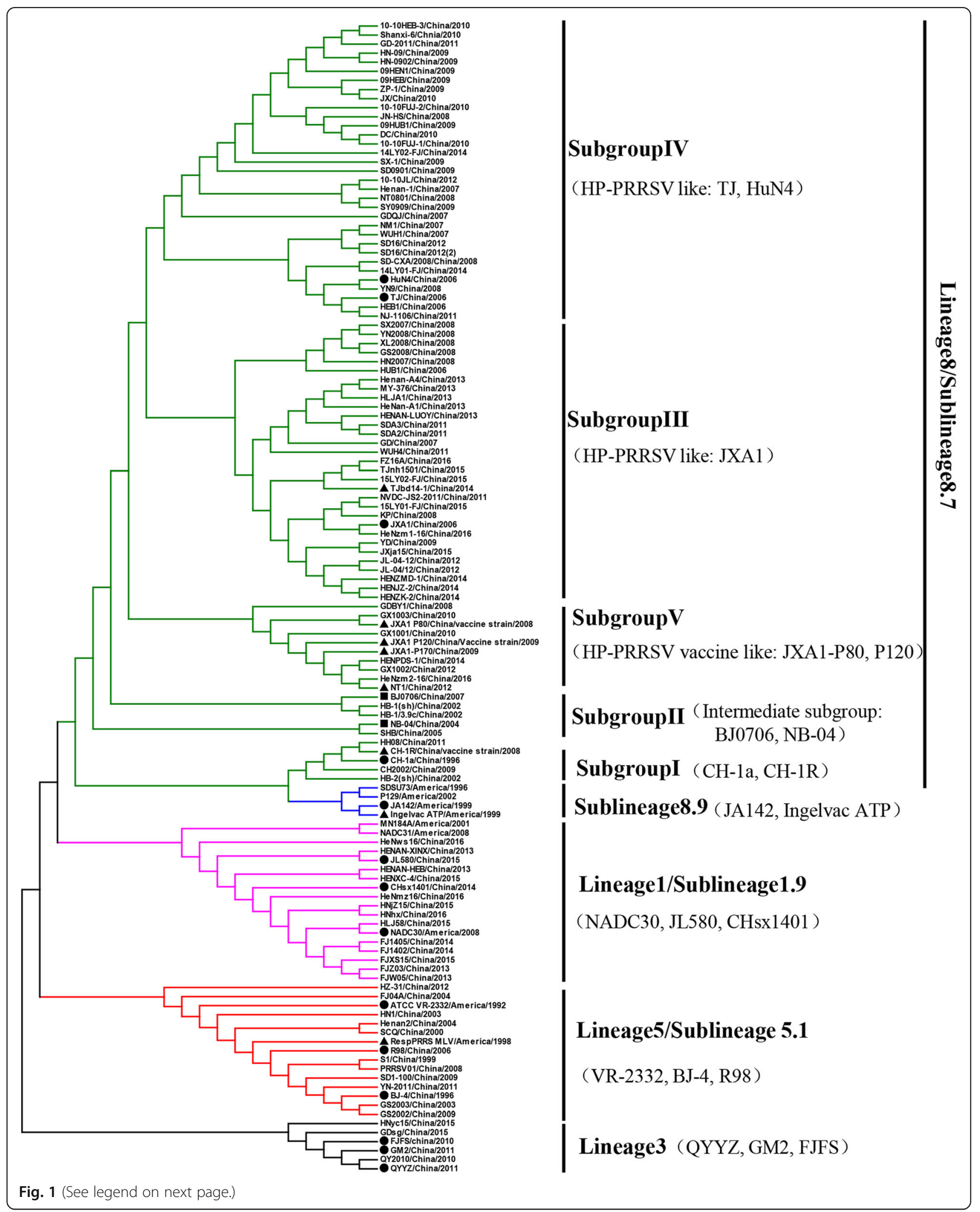


(See figure on previous page.)

Fig. 1 The phylogenetic analysis based on ORF5 genes from 127 reference virus strains of PRRSV-2. The unrooted phylogenetic tree was constructed using the distanced-based neighbor-joining method in MEGA6.0 with bootstrap values (1000 replicates). The PRRSV-2 circulating in China were clustered into four lineages. Lineage 8 is predominant in 1996-2016 in China and could be further subdivided into five subgroups. Lineage 1 spreads rapidly since 2013 in China. The lineages are according to previous report. The circles (•) indicate the representative virus strains of each lineage in China. The triangles $(\mathbf{\Lambda})$ mean the attenuated live vaccine strains or vaccine derivatives. The squares ( $\mathbf{\square})$ represent two transition virus strains

$\left(\mathrm{S} / \mathrm{C}^{\mathrm{LV}}\right), 123\left(\mathrm{~L} / \mathrm{F}^{\mathrm{LV}}\right), 155\left(\mathrm{I} / \mathrm{V}^{\mathrm{LV}}\right), 173\left(\mathrm{G} / \mathrm{D}^{\mathrm{LV}}\right)$ and 175 $\left(\mathrm{D} / \mathrm{N}^{\mathrm{LV}}\right)$ are much conserved mutations in Chinese virus strains.

\section{$\mathrm{N}$ protein polymorphism}

Normally the $\mathrm{N}$ protein is highly conserved. In genotype 1 PRRSV, $\mathrm{N}$ protein, as well as the high variable ORF5 and Nsp2 genes, is found to be very pleomorphic. The length of $\mathrm{N}$ protein ranges from 124 to 132aa [59-61]. Concretely, subtype 1 is 128aa (occasional 126/129/ 132aa), subtype 2 is 125 aa (occasional 124/131aa), while subtype 3 is 124aa (occasional 128aa) [62]. In China, the $\mathrm{N}$ protein length of all the isolates is 128aa excepted NVDC-NM2 (Genbank ID: KC492504) strain which is 129aa and a Ser was inserted between 87th and 88th site. Based on the alignment assay (Fig. 4), the $13\left(\mathrm{~N} / \mathrm{S}^{\mathrm{LV}}\right)$, $100\left(\mathrm{G} / \mathrm{S}^{\mathrm{LV}}\right), 128\left(\mathrm{~N} / \mathrm{S}^{\mathrm{LV}}\right)$ sites are conserved mutations among Chinese isolated virus strains.

\section{Pathogenicity and recombination}

To our knowledge, until now only two Chinese PRRSV1 isolations, GZ11-G1 and HLJB1, to be evaluated the pathigenicity. These two strains are pathogenic to piglets and can lead to classic PRRSV-specific lesions. The infectious pigs showed mild clinical signs and no pigs died, which indicated they are less virulent [58, 63]. Interestingly, both of them belong to subgroup I-the Amervac PRRSV vaccine-related strains. HLJB1 and GZ11-G1 show $91.64 \%$ and $96.3 \%$ genome homology with the Amervac PRRSV virus, respectively [58, 63]. Additionally, recombination analyses showed that HLJB1 is a recombinant from the Amervac vaccine and the BJEU06-1 isolate [64]. It is necessary to routinely monitor the prevalence of PRRSV-1 in the fields and more research needs bo be done for better understanding the biological and pathogenic characteristics of PRRSV-1 in China.

\section{Control strategies \\ Vaccination}

It is still a controversial question about the usage of PRRSV vaccines. On one hand, the vaccine efficiency is low or not significant from the clinical observation. On the other hand, there are no better choices currently under the circumstances of PRRSV pandemics. In China, there are more than seven commercial PRRSV vaccines (CH-1a/CH-1R, VR2332/Ingelvac PRRS MLV, R98/R98 MLV, JXA1/JXA1-R, TJ/TJM-F92, HuN4/HuN4-F112, GD/GDr180, etc) used. These vaccines are effective in reducing clinical signs, decreasing viremia and

Table 2 The recombinant virus strains and the recombination regions

\begin{tabular}{|c|c|c|c|c|c|c|}
\hline No. & Recombinant strains & Major parent & Minor parent & Recombination regions & Virulence & Reference \\
\hline 1 & $J L 580^{a}$ & NADC30 ${ }^{\mathrm{a}}$ & HP-PRRSV (09HEN1) & Nsp2, Nsp3 Nsp7, ORF2a ORF4 & Highly Pathogenic & {$[23]$} \\
\hline 2 & FJ1402 ${ }^{\mathrm{a}}$ & NADC $30^{\mathrm{a}}$ & HP-PRRSV (GD) & Nsp2 Nsp3, Nsp12 ORF3 & Highly Pathogenic & [47] \\
\hline 3 & HENAN-HEB ${ }^{a}$ & $15 \mathrm{HEN}^{\mathrm{a}}{ }^{\mathrm{a}}$ & HP-PRRSV (JXA1) & Nsp2 & & [48] \\
\hline 4 & TJnh1501 & $\mathrm{CHs} \times 1401^{\mathrm{a}}$ & TJbd14-1 ${ }^{b}$ & Nsp2 & intermediate virulence & [49] \\
\hline 5 & FJW05 ${ }^{a}$ & JXA1-P80 ${ }^{b}$ & $\mathrm{FJZO3}^{\mathrm{a}}$ & Nsp1-ORF5 & Highly Pathogenic & [50] \\
\hline 6 & FJXS15 ${ }^{\mathrm{a}}$ & & & & & [51] \\
\hline 7 & $\mathrm{HNhx}^{\mathrm{a}}$ & HENAN-HEB ${ }^{a}$ & HP-PRRSV (JXA1) & Nsp4 Nsp9 & & [46] \\
\hline 8 & HNyc15 ${ }^{\mathrm{a}}$ & $15 S C 3^{\mathrm{a}}$ & $\mathrm{CH}-1 \mathrm{a} / \mathrm{NR} 2332$ & ORF2 ORF4 & & {$[52]$} \\
\hline 9 & HENAN-XINX & $\operatorname{NADC} 30^{\mathrm{a}}$ & VR-2332 & Nsp2 Nsp5 & & [48] \\
\hline 10 & Chs $\times 1401^{a}$ & HENAN-XINX ${ }^{a}$ & VR-2332 & Nsp11 & intermediate virulence & [49] \\
\hline 11 & SY0909 & HP-PRRSV (JXA1) & NT0801 & Nsp12 ORF5 & & This study \\
\hline 12 & GDsg & QYYZ & JXA1-P80 & Nsp9 Nsp11 & & {$[82]$} \\
\hline 13 & GM2 & QYYZ & RespPRRS MLV ${ }^{b}$ & Nsp7 Nsp11 & & {$[54]$} \\
\hline 14 & HB-1(sh)/2002 & $\mathrm{HB}-1 / 3.9 \mathrm{C}$ & $\mathrm{CH}-1 \mathrm{a}$ & ORF2a ORF4 & & This study \\
\hline 15 & HNjz15 & / & / & / & intermediate virulence & {$[55]$} \\
\hline
\end{tabular}

"a" means NADC30 or NADC30-like virus strains. "b" indicates modified live vaccine strains or vaccine derivative strain. The recombination events were detected by RDP4 program using seven different algorithms (RDP, GeneConv, BootScan, MaxChi, Chimera, SiScanm and 3Seq) 
Table 3 The reference sequence information of PRRSV-1

\begin{tabular}{|c|c|c|c|c|c|c|c|c|c|}
\hline No. & Virus strain & Origin & Accession no. & Subtype & No. & Virus strain & Origin & Accession no. & Subtype \\
\hline 1 & Lelystad & Netherlands, 1991 & M96262 & Subtype1 & 23 & SDRPIV4A & France, 1992 & AY035919 & Subtype 1 \\
\hline 2 & BJEU06-1 & Beijing, China, 2006 & GU047344 & Subtype1 & 24 & NY3-D769 & England, 1992 & AY035940 & Subtype1 \\
\hline 3 & NMEU09-1 & Inner Mongolia, China, 2009 & GU047345 & Subtype1 & 25 & L1-D767 & England, 1992 & AY035939 & Subtype1 \\
\hline 4 & NMEU09-2 & Inner Mongolia, China, 2009 & GU047340 & Subtype1 & 26 & 24,554 & Denmark, 1997 & AY035910 & Subtype1 \\
\hline 5 & SHE & Shanghai, China, 2009 & GQ461593 & Subtype1 & 27 & 28,639 & Denmark, 1998 & AY035912 & Subtype1 \\
\hline 6 & NVDC-NM1 & Inner Mongolia, China, 2011 & JX187609 & Subtype1 & 28 & LV4.2.1 & Netherlands, 2004 & AY588319 & Subtype 1 \\
\hline 7 & NVDC-NM2 & Inner Mongolia, China, 2011 & KC492504 & Subtype1 & 29 & EuroPRRSV & USA, 1999 & AY366525 & Subtype1 \\
\hline 8 & NVDC-NM3 & Inner Mongolia, China, 2011 & KC492505 & Subtype1 & 30 & SD-01-08 & USA, 2001 & DQ489311 & Subtype 1 \\
\hline 9 & NVDC-FJ & Fujian, China, 2011 & KC492506 & Subtype1 & 31 & MN-03-08_EU & USA, 2003 & AY749385 & Subtype1 \\
\hline 10 & FJEU13 & Fujian, China, 2013 & KP860912 & Subtype1 & 32 & MN-03-10_EU & USA, 2003 & AY749389 & Subtype 1 \\
\hline 11 & FJQEU14 & Fujian, China, 2014 & KP860913 & Subtype1 & 33 & SDPRRS 04-40 & USA, 2004 & EF175566 & Subtype1 \\
\hline 12 & B13 & China, 1999 & AY633973 & Subtype1 & 34 & SDPRRS 04-48 & USA, 2004 & AY749411 & Subtype 1 \\
\hline 13 & FJ0603 & Fujian, China, 2006 & HM114313 & Subtype1 & 35 & Amervac & Spain,Vaccine & GU067771 & Subtype1 \\
\hline 14 & GZ11-G1 & Guizhou, China, 2011 & KF001144 & Subtype1 & 36 & BH_95/10-12 & Germany, 2006 & JN651738 & Subtype1 \\
\hline 15 & LNEU12 & Liaoning, China, 2012 & KM196101 & Subtype1 & 37 & 2.46 & Germany, 1993 & AY035923 & Subtype1 \\
\hline 16 & HKEU16 & Hong Kong, China, 2007 & EU076704 & Subtype1 & 38 & Vas & Belarus, 2005 & DQ324689 & Subtype2 \\
\hline 17 & HLJB1 & Heilongjiang, China, 2014 & KT224385 & Subtype1 & 39 & SHV & Russia, 2006 & EU071236 & Subtype2 \\
\hline 18 & HK3 & Hong Kong, China, 2003 & KF287129 & Subtype1 & 40 & Bor-41 & Belarus, 2004 & DQ324671 & Subtype2 \\
\hline 19 & HK5 & Hong Kong, China, 2004 & KF287130 & Subtype1 & 41 & Lena & Belarus, 2007 & JF802085 & Subtype3 \\
\hline 20 & HK10 & Hong Kong, China, 2004 & KF287131 & Subtype1 & 42 & Zad-1 & Belarus, 2004 & DQ324694 & Subtype3 \\
\hline $21^{\circ}$ & FJ0602 & Fujian, China, 2006 & HM755885 & Subtype1 & 43 & SOZ-6 & Belarus, 2004 & DQ324686 & Subtype 3 \\
\hline 22 & SDRPV4A & France, 1993 & AY035920 & Subtype1 & & & & & \\
\hline
\end{tabular}

shortening duration of viral shedding. They can provide an efficient protection against a lethal challenge with their respective parental HP-PRRSV isolates [32-34, 6567]. However, they can not completely prevent infection and establish sterilizing immunity. Also, the vaccine efficiency significantly decreases against heterologous challenge, and they can only provide partial or limited protection $[47,65,68,69]$. The outbreak of HP-PRRSV in 2006 is in the backgroud of vaccination with $\mathrm{CH}-1 \mathrm{a}$ and Ingelvac PRRS MLV. Since 2013, NADC30-like virus strains transmitted quickly around herds in China although massive vaccination with all the commercial vaccines.

Massive vaccination with live attenuated vaccines also leads to safety concern and more genetic divergence: (i) It has been demonstrated that vaccine viruses could spread from vaccinated pigs to non-vaccinated, suggesting their ability to circulate in the fields and form different vaccine-associated clusters [70, 71]; (ii) The extensive immune pressure maybe serve as a major driving force which greatly promotes genetic diversity of genotype 2 in China [72]; (iii) Revertants from the vaccine derivatives should be paid more attention to. Indeed, there are several reports about the attenuated vaccine reverting to a virulent type [49, 73]; (iv) The frequency of recombination is increasing, especially the emergence of NADC30-like virus strains (lineage1) which display a wide broad recombination ability with HP-PRRSV (JXA1), classical PRRSV (CH-1a,VR2332) and attenuated vaccines (JXA1-P80, TJM-F92-like) [46, 49, 52, 74]. It has been verified that recombination is associated with re-prevalence of HPPRRSV during 2009 to 2010 and closely related with the pandemic of NADC30-like virus since 2013 in China $[24,53]$. Accordingly, veterinarians and farmers become more cautious and re-evaluate the previous immune strategies. Some farmers are trying to reduce and stop the vaccination of PRRSV in China by taking other comprehensive PRRS prevention and control measures.

\section{Production system and biosecurity}

It is confirmed that multiple production sites and high quality biosecurity system are important in PRRSV prevention and control $[75,76]$. Due to historical reasons, most of Chinese pig farms are one production site and the layout of gestation, farrowing, nursery and growing are also not reasonable. Many farms are still continuous flow sites and lack good biosecurity system. Following the development of swine production in China, more and more pig producers have recognized the significance of management, production system, environment 


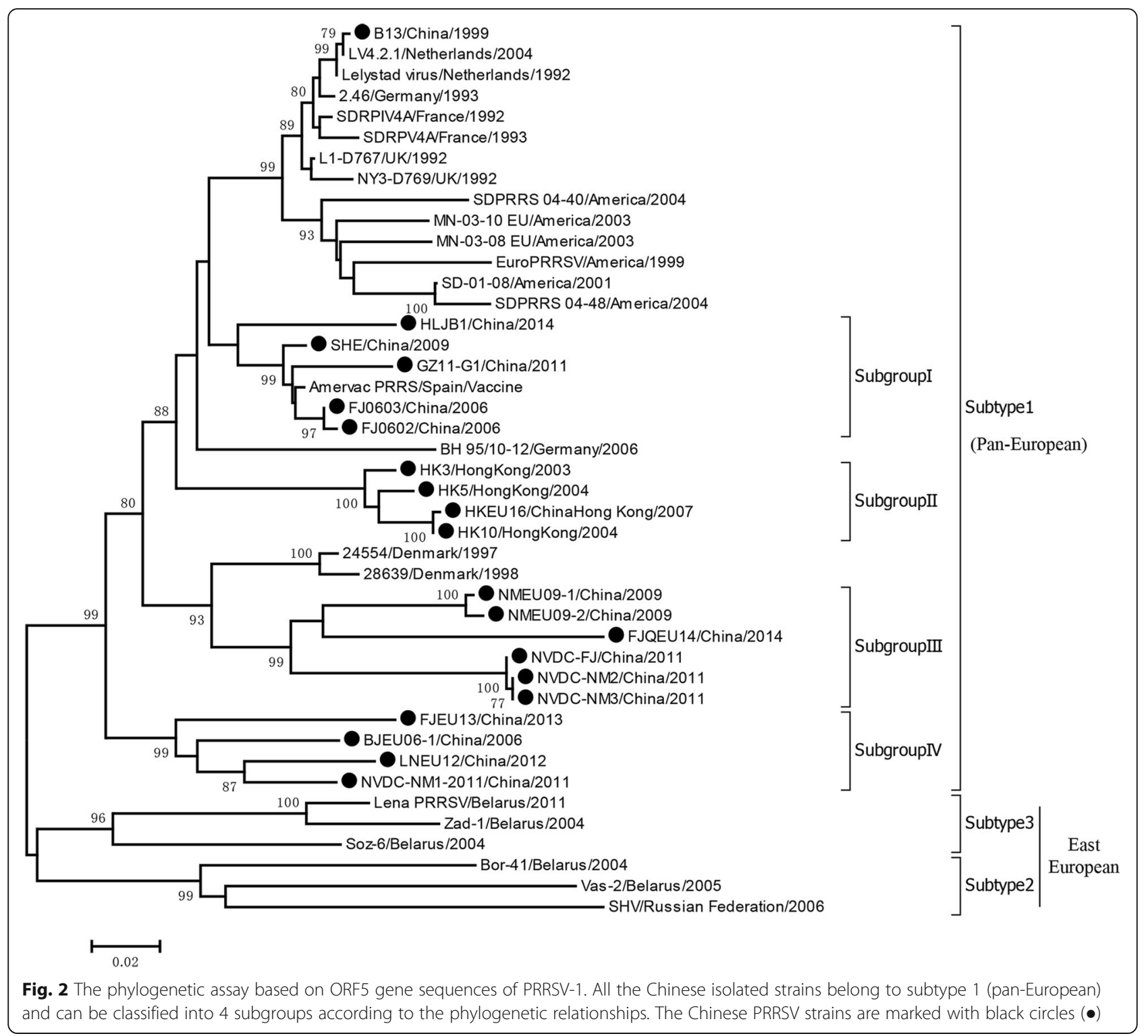

control and good biosecurity. They have changed their views that only or over-dependent vaccination could prevent porcine diseases and would like to invest more in nutrition, management, environment, biosecurity and application of new technologies. For example, airfiltration ventilation systems were used by some breeding companines; gilts acclimation and strict batch production (also known as "All in All out", AIAO) were accepted and implemented by more commercial pig farms.

The strategy of "load, close, homogenise" (LCH)

The load, close, homogenise (LCH) strategy (also known as load, close, expose) was extensively accepted in PRRV control and elimination for it's inexpensive and easy operability [75, 77, 78]. To perform this strategy, the producer should load enough gilts once for minimum of 200 days and then implement herd closure. The key points are gilts acclimation and good biosecurity system. Poul H. Rathkjen and Johannes Dall summarized ten golden rules for biosecurity management and showed a good model for successful implement of LCH [76]. Uniform PRRS status could be achieved either by simultaneous vaccination or by inoculation with serum containing resident virus. Notably, it should be very cautious when used the virus positive serum for acclimation because of the virulence of HP-PRRSV.

It is a better choice to build regional elimination of PRRSV. This model was successfully implemented in the state of Minnesota of the United States and in Horne Peninsula of the Denmark $[75,76]$. They are good examples for HP-PRRSV regional elimination in China. This 


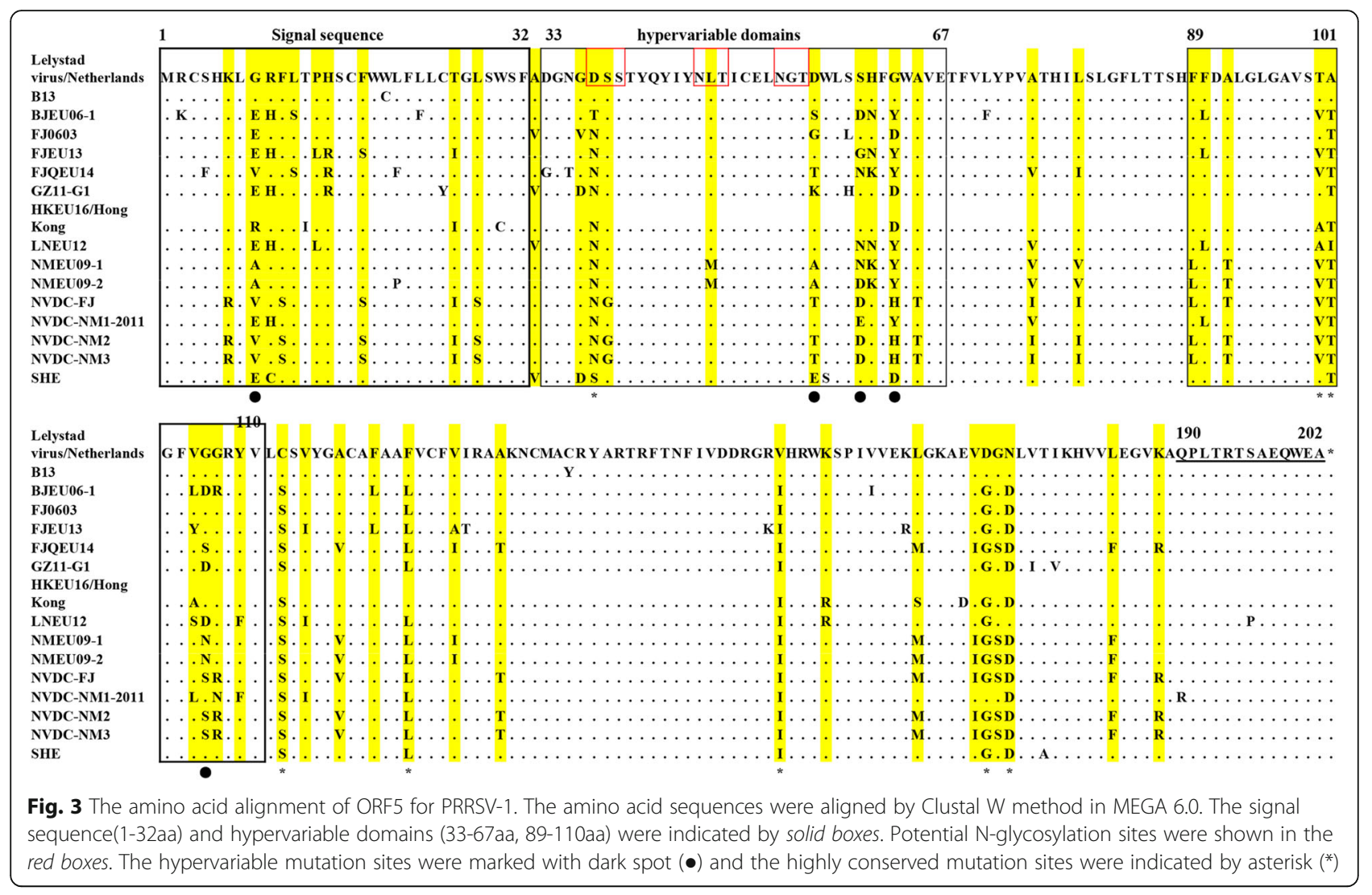

project needs close collaboration among veterinarians, pig producers and regional governments.

\section{Future perspective}

Based on the ORF5 sequence analysis of PRRSV, we systematically retrospect the history and prevalence of PRRSV in China from a molecular perspective. PRRSV diverged earlier in the origin, and the early isolated strain $\mathrm{CH}-1 \mathrm{a}$ and $\mathrm{BJ}-4$ only share $91.4 \%$ homology. $\mathrm{CH}-1 \mathrm{a}$ belongs to sublineage 8.7 and BJ-4 is clustered into sublineage 5.1. BJ-4 is likely to be imported from the North America or maybe as a vaccine strain since it shares $99.6 \%$ and $99.8 \%$ identity with VR2332 and RespPRRS MLV, respectively. It is still not clear why sublineage 5.1 is relatively stable and shows limited epidemicity. Nevertheless, sublineage8.7 is pandemic and goes through such genetic diversity, especially the emergence of HP-PRRSV which is devastating to swine production in China. Although the vaccines derived from HP-PRRSV play a role in reducing the severe clinical signs and slowing the prevalence of PRRS, it is still far away from expectation. And the massive usage of vaccines also lead to some side effects including virulence reversion of attenuated live vaccines $[49,73]$, markedly increase in virus recombination and variation $[50,53,72,74]$.
Recently, lineage 3 and lineage 1 are also circulating in Chinese swine herds. Lineage 3 is mainly limited in south of China (Jiangxi, Henan, Jiangsu, Guangdong, Guangxi) [38, 43]. Lineage 1 was firstly reported in Henan province in 2013 [45, 79], and then this lineage transmitted quickly in northeast, southeast, central and east of China. They lead to pandemic of PRRSV in China $[38,40,80,81]$. The commercial vaccines seem not efficient since the dissemination of lineage 1 is under the background of massive vaccination. Several studies also show the commercial vaccines only provide limited or partial protection $[38,68,69]$. These facts prompt people to re-evaluate the strategies of prevention and control of PRRSV in China. And people become more cautious on massive vaccination. More and more farms try to improve management, biosecurity and environment instead of only over-dependent on vaccines.

Several studies showed the prevalence of PRRSV-1 in China, and up to 9 provinces and regions have been reported until now $[38,56-58]$. All the Chinese circulating strains share some special common amino acids compared with Lylestad virus. Although the PRRSV-1 PRRSV is sporadic in China, we should pay more attention since there are no vaccines to be provided.

It has been 30 years since the first PRRS report in 1987 in America. Originally, we call it Mystery Swine 


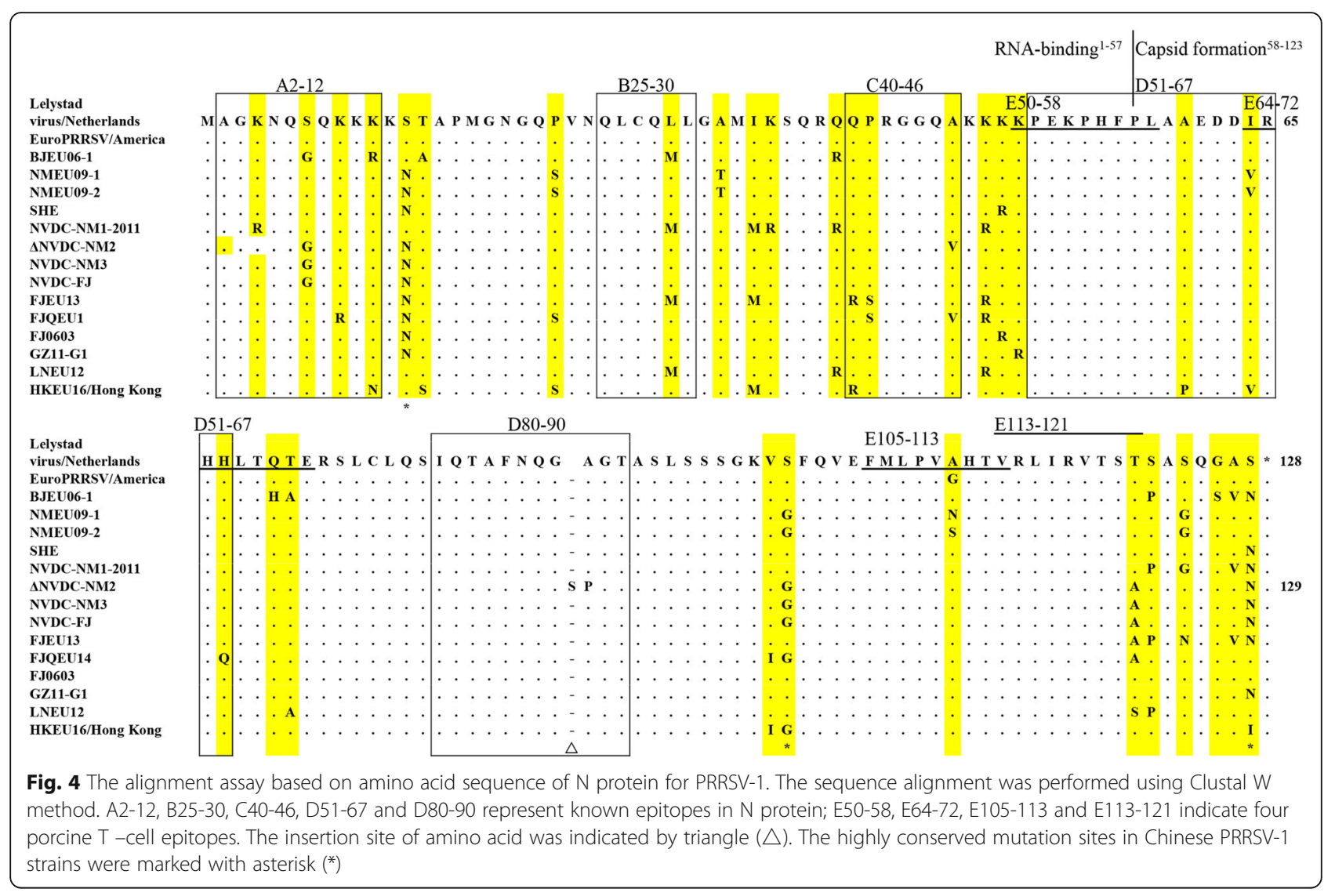

Disease (MSD) [3, 7]. Thirty years later, although we have a deep understanding on clinical onset characteristics of PRRS, molecular epidemiology, virus proliferation, pathogenic mechanism, immune response and immune escape mechanism, PRRSV is still mysterious to us and we have not found a successful prevention and eradication strategy. There are still more questions need to be elucidated: i) What is the molecular mechanism of high variation and recombination frequency of PRRSV; ii) The broad spectrum neutralizing antibodies need to be analyzed further; iii) It remains to be elucidated that determination factors of virulence difference among different PRRSV strains; iv) How to look for a new vaccine development strategy which is safe, high efficient and have a broad spectrum protection to different PRRSV lineages. The clarification of these problems would provide great help and support for ultimate PRRSV control.

\section{Conclusion}

PRRSV is still one of the most important causative agents to the swine production worldwide and causes huge economic losses every year. In China, although several commercial attenuated live vaccines have been widely used, PRRS is still severe in the pig industry. Moreover, the genetic diversity and complexity of PRRSV were further increasing. In this review, we systematically analyzed the
PRRSV prevalent history and genetic evolution in China using a molecular epidemiological perspective. Additionally, we summarized the effective strategies and discussed the current problems in the prevention and control of PRRS. Our analysis would provide valuable information and new insights for the PRRSV epidemic trends and control strategies in China.

\section{Abbreviations}

HP-PRRSV: Highly pathogenic PRRSV; ORFs: Open reading frames; PRRS: Porcine reproductive and respiratory syndrome; PRRSV: PRRS virus; SIRS: Swine infertility and respiratory syndrome; UTR: Untranlated region

\section{Acknowledgements}

Not applicable.

\section{Funding}

This work was funded by grants from the National Key Research and Development Progrom of China (2016YFD0500709), China Agriculture Research System (No.CARS 35).

\section{Availability of data and materials}

Not applicable.

\section{Authors' contributions}

ZG and X-XC wrote the manuscript. RL and SQ revised the manuscript critically for important intellectual content. ZG and GZ conceived the outline and content of the review. All authors have read and approved the submitted manuscript.

Ethics approval and consent to participate Not applicable. 


\section{Consent for publication}

Not applicable.

\section{Competing interests}

The authors declare that they have no competing interests.

\section{Publisher's Note}

Springer Nature remains neutral with regard to jurisdictional claims in published maps and institutional affiliations.

\section{Author details}

${ }^{1}$ Key Laboratory of Animal Immunology of the Ministry of Agriculture, Henan Provincial Key Laboratory of Animal Immunology, Henan Academy of Agricultural Sciences, Zhengzhou 450002, People's Republic of China. ${ }^{2}$ College of Animal Science and Veterinary Medicine, Henan Agricultural University, Zhengzhou 450002, People's Republic of China. ${ }^{3}$ Jiangsu Co-innovation Center for Prevention and Control of Important Animal Infectious Diseases and Zoonoses, Yangzhou 225009, People's Republic of China.

\section{Received: 30 October 2017 Accepted: 12 December 2017}

\section{Published online: 04 January 2018}

\section{References}

1. Holtkamp DJ, Kliebenstein JB, Neumann EJ, Zimmerman JJ, Rotto HF, Yoder TK, Wang C, Yeske PE, Mowrer CL, Haley CA. Assessment of the economic impact of porcine reproductive and respiratory syndrome virus on United States pork producers. J Swine Health Prod. 2013;21(2):72-84.

2. Keffaber KK. Reproductive failure of unknown etiology. Am. Assoc. swine Pract. Newsletter. 1989;1:1-9.

3. Wensvoort G, Terpstra C, Pol JM, ter Laak EA, Bloemraad M, de Kluyver EP Kragten C, van Buiten L, den Besten A, Wagenaar F, Et A. Mystery swine disease in The Netherlands: the isolation of Lelystad virus. Vet Q. 1991;13: 121-30.

4. Chang CC, Chung WB, Lin MW, Weng CN, Yang PC, Chiu YT, Chu RM Porcine reproductive and respiratory syndrome (PRRS) in Taiwan. I. Viral isolation. J Chin Soc Vet Sci. 1993:19(4):268-76.

5. Baron T, Albina E, Leforban $Y$, Madec F, Guilmoto H, Plana DJ, Vannier P. Report on the first outbreaks of the porcine reproductive and respiratory syndrome (PRRS) in France. Diagnosis and viral isolation. Ann Rech Vet. 1992;23:161-6.

6. Kuwahara H, Nunoya T, Tajima M, Kato A, Samejima T. An outbreak of porcine reproductive and respiratory syndrome in Japan. J Vet Med Sci. 1994:56:901-9.

7. Collins JE, Benfield DA, Christianson WT, Harris L, Hennings JC, Shaw DP, Goyal SM, McCullough S, Morrison RB, Joo HS, Et A. Isolation of swine infertility and respiratory syndrome virus (isolate ATCC VR-2332) in North America and experimental reproduction of the disease in gnotobiotic pigs. J Vet Diagn Investig. 1992;4:117-26.

8. Wensvoort G, de Kluyver EP, Pol JM, Wagenaar F, Moormann RJ, Hulst MM, Bloemraad R, den Besten A, Zetstra T, Terpstra C. Lelystad virus, the cause of porcine epidemic abortion and respiratory syndrome: a review of mystery swine disease research at Lelystad. Vet Microbiol. 1992;33:185-93.

9. Carman S, Sanford SE, Dea S. Assessment of seropositivity to porcine reproductive and respiratory syndrome (PRRS) virus in swine herds in Ontario-1978 to 1982. Can Vet J. 1995;36:776-7.

10. Cavanagh D. Nidovirales: a new order comprising Coronaviridae and Arteriviridae. Arch Virol. 1997;142:629-33.

11. Allende R, Lewis TL, Lu Z, Rock DL, Kutish GF, Ali A, Doster AR, Osorio FA. North American and European porcine reproductive and respiratory syndrome viruses differ in non-structural protein coding regions. J Gen Virol. 1999:80(Pt 2):307-15.

12. Firth AE, Zevenhoven-Dobbe JC, Wills NM, Go YY, Balasuriya UB, Atkins JF, Snijder EJ, Posthuma CC. Discovery of a small arterivirus gene that overlaps the GP5 coding sequence and is important for virus production. J Gen Virol. 2011;92:1097-106.

13. Johnson CR, Griggs TF, Gnanandarajah J, Murtaugh MP. Novel structural protein in porcine reproductive and respiratory syndrome virus encoded by an alternative ORF5 present in all arteriviruses. J Gen Virol. 2011;92:1107-16.

14. van Dinten LC, Rensen S, Gorbalenya AE, Snijder EJ. Proteolytic processing of the open reading frame $1 \mathrm{~b}$-encoded part of arterivirus replicase is mediated by nsp4 serine protease and is essential for virus replication. J Virol. 1999:73:2027-37.

15. Meng XJ, Paul PS, Halbur PG, Lum MA. Phylogenetic analyses of the putative $M$ (ORF 6) and N (ORF 7) genes of porcine reproductive and respiratory syndrome virus (PRRSV): implication for the existence of two genotypes of PRRSV in the U.S.A. and Europe. Arch Virol. 1995;140:745-55.

16. Kuhn JH, Lauck M, Bailey AL, Shchetinin AM, Vishnevskaya TV, Bào Y, Ng TFF, LeBreton M, Schneider BS, Gillis A, Tamoufe U, Diffo JLD, Takuo JM, Kondov NO, Coffey LL, Wolfe ND, Delwart E, Clawson AN, Postnikova E, Bollinger L, Lackemeyer MG, Radoshitzky SR, Palacios G, Wada J, Shevtsova ZV, Jahrling PB, Lapin BA, Deriabin PG, Dunowska M, Alkhovsky SV, Rogers J, Friedrich TC, O Connor DH, Goldberg TL. Reorganization and expansion of the nidoviral family Arteriviridae. Arch Virol. 2016;161:755-68.

17. Darwich L, Gimeno M, Sibila M, Diaz I, de la Torre E, Dotti S, Kuzemtseva L, Martin M, Pujols J, Mateu E. Genetic and immunobiological diversities of porcine reproductive and respiratory syndrome genotype I strains. Vet Microbiol. 2011:150:49-62.

18. Shi M, Lam TT, Hon CC, Hui RK, Faaberg KS, Wennblom T, Murtaugh MP, Stadejek T, Leung FC. Molecular epidemiology of PRRSV: a phylogenetic perspective. Virus Res. 2010;154:7-17.

19. Shi M, Lam TTY, Hon CC, Murtaugh MP, Davies PR, Hui RKH, Li J, Wong LTW, Yip CW, Jiang JW, Leung FCC. Phylogeny-based evolutionary, demographical, and geographical dissection of north American type 2 porcine reproductive and respiratory syndrome viruses. J Virol. 2010;84:8700-11.

20. Mengeling WL, Lager KM, Vorwald AC. Clinical consequences of exposing pregnant gilts to strains of porcine reproductive and respiratory syndrome (PRRS) virus isolated from field cases of "atypical" PRRS. Am J Vet Res. 1998; 59:1540-4.

21. Han J, Wang Y, Faaberg KS. Complete genome analysis of RFLP 184 isolates of porcine reproductive and respiratory syndrome virus. Virus Res. 2006; 122:175-82

22. Karniychuk UU, Geldhof M, Vanhee M, Van Doorsselaere J, Saveleva TA, Nauwynck HJ. Pathogenesis and antigenic characterization of a new east European subtype 3 porcine reproductive and respiratory syndrome virus isolate. BMC Vet Res. 2010;6:30

23. Tian K, Yu X, Zhao T, Feng Y, Cao Z, Wang C, Hu Y, Chen X, Hu D, Tian X, Liu D, Zhang S, Deng X, Ding Y, Yang L, Zhang Y, Xiao H, Qiao M, Wang B, Hou L, Wang $X$, Yang $X$, Kang L, Sun $M$, Jin P, Wang S, Kitamura Y, Yan J, Gao GF. Emergence of fatal PRRSV variants: unparalleled outbreaks of atypical PRRS in China and molecular dissection of the unique hallmark. PLoS One. 2007;2:e526.

24. Zhao K, Ye C, Chang X, Jiang C, Wang S, Cai X, Tong G, Tian Z, Shi M, An T. Importation and recombination are responsible for the latest emergence of highly pathogenic porcine reproductive and respiratory syndrome virus in China. J Virol. 2015:89:10712-6.

25. Zhou L, Wang Z, Ding Y, Ge X, Guo X, Yang H. NADC30-like strain of porcine reproductive and respiratory syndrome virus, China. Emerg Infect Dis. 2015;21:2256-7.

26. Kumar S, Stecher G, Peterson D, Tamura K. MEGA-CC: computing core of molecular evolutionary genetics analysis program for automated and iterative data analysis. Bioinformatics. 2012:28:2685-6.

27. Martin DP, Murrell B, Golden M, Khoosal A, Muhire B. RDP4: detection and analysis of recombination patterns in virus genomes. Virus Evol. 2015;1:v3.

28. Guo BQ, Chen ZS, Liu WX, Cui YZ. Isolation and identification of procine reproductive and respiratory syndrome virus from aborted fetues suspected of PRRS. Chin J Anim Poult Infect Dis. 1996;87(02):1-5. (in Chinese)

29. Yang HC, Guan SH, Yi XM, Gan MH. Isolation and identification of porcine reproductive and respiratory syndrome. Chin J Vet Med. 1997;10:9-10. (in Chinese)

30. Jian ZY, Ma ZY, Jiang P, Zhang ZX, Cai BX. Serological investigation of porcine reproductive and respiratoryu syndrome (PRRS): a preliminary report. Anim Husbandry Vet Med. 1996;6:11-2. (In Chinese)

31. Chen BW, Sun YJ, Luo CB, Sun YF, Pan FC, Lin ZX, Su YS, Li SG, Tong KZ. Isolation and identification of porcine reproductive and respiratory syndrome (PRRS) virus: a preliminary report. Chin J Vet Med. 1996;5:6-8. (In Chinese)

32. Han $W$, JJ W, Deng XY, Cao Z, XL Y, Wang CB, Zhao TZ, Chen NH, HH H, Bin W, Hou LL, Wang LL, Tian KG, Zhang ZQ. Molecular mutations associated with the in vitro passage of virulent porcine reproductive and respiratory syndrome virus. Virus Genes. 2009;38:276-84.

33. Leng X, Li Z, Xia M, Li X, Wang F, Wang W, Zhang X, Wu H. Mutations in the genome of the highly pathogenic porcine reproductive and respiratory 
syndrome virus potentially related to attenuation. Vet Microbiol. 2012; 157:50-60.

34. Tian ZJ, An TQ, Zhou YJ, Peng JM, SP H, Wei TC, Jiang YF, Xiao Y, Tong GZ. An attenuated live vaccine based on highly pathogenic porcine reproductive and respiratory syndrome virus (HP-PRRSV) protects piglets against HP-PRRS. Vet Microbiol. 2009;138:34-40.

35. Li C, Zhuang J, Wang J, Han L, Sun Z, Xiao Y, Ji G, Li Y, Tan F, Li X, Tian K. Outbreak investigation of NADC30-like PRRSV in south-East China. Transbound Emerg Dis. 2016;63:474-9.

36. Zhao Y, Luo CB, Lin ZX, Chen R, Li SG, Chen BW, Liu SG. Expression of ORF5 gene of porcine reproductive and respiratory syndrome virus B13 strain in a baculovirus expression system. J AGR BIOT. 2000;3:211-5. (in Chinese)

37. Chen N, Cao Z, Yu X, Deng X, Zhao T, Wang L, Liu Q, Li X, Tian K. Emergence of novel European genotype porcine reproductive and respiratory syndrome virus in mainland China. J Gen Virol. 2011;92:880-92.

38. Gao JC, Xiong JY, Ye C, Chang XB, Guo JC, Jiang CG, Zhang GH, Tian ZJ, Cai $X H$, Tong GZ, An TQ. Genotypic and geographical distribution of porcine reproductive and respiratory syndrome viruses in mainland China in 19962016. Vet Microbiol. 2017;208:164-72.

39. Deng Y, Pan Y, Wang D, Zhou Q, Bi Y, Chen F, Song Y. Complete genome sequence of porcine reproductive and respiratory syndrome virus strain QY2010 reveals a novel subgroup emerging in China. J Virol. 2012;86: 7719-20.

40. Liu J, Zhou X, Zhai J, Li B, Wei C, Dai A, Yang X, Luo M. Genetic diversity and evolutionary characteristics of type 2 porcine reproductive and respiratory syndrome virus in southeastern China from 2009 to 2014. Arch Virol. 2017;

41. Zhou L, Yang H. Porcine reproductive and respiratory syndrome in China. Virus Res. 2010;154:31-7.

42. Wu Q, Li Z, Zhang G, Niu J, Zeng X, Sun B, Ma J. Genetic diversity and phylogenetic analysis of porcine reproductive and respiratory syndrome virus in southern China from 2007 to 2014. J Vet Sci. 2017;18:317.

43. WH L, Tun HM, Sun BL, Mo J, Zhou QF, Deng YX, Xie QM, Bi YZ, Leung FC, Ma JY. Re-emerging of porcine respiratory and reproductive syndrome virus (lineage 3) and increased pathogenicity after genomic recombination with vaccine variant. Vet Microbiol. 2015;175:332-40.

44. Zhou F, Chang HT, Zhao J, Chen L, Wang XW, Liu HY, Yao HX, Wang CQ, Wang $X$. Identification and molecular epidemiology of porcine reproductive and respiratory syndrome virus prevailing in Henan province from 2012 to 2013. Chin J Vet Sci. 2014;9:1398-404. (in Chinese)

45. Wang LJ, Xie W, Chen XX, Qiao S, Zhao M, Gu Y, Zhao BL, Zhang G. Molecular epidemiology of porcine reproductive and respiratory syndrome virus in Central China since 2014: the prevalence of NADC30-like PRRSVs. Microb Pathog. 2017;109:20-8.

46. Wang LJ, Guo Z, Qiao S, Chen XX, Zhang G. Complete genome sequence of a mosaic NADC30-like porcine reproductive and respiratory syndrome virus in China. Genome Announc. 2016;4

47. Zhang Q, Jiang P, Song Z, LV L, Li L, Bai J. Pathogenicity and antigenicity of a novel NADC30-like strain of porcine reproductive and respiratory syndrome virus emerged in China. Vet Microbiol. 2016;197:93-101.

48. Li X, Bao H, Wang Y, Tian K. Widespread of NADC30-like PRRSV in China: another Pandora's box for Chinese pig industry as the outbreak of highly pathogenic PRRSV in 2006? Infect Genet Evol. 2017;49:12-3.

49. Bian T, Sun Y, Hao M, Zhou L, Ge X, Guo X, Han J, Yang H. A recombinant type 2 porcine reproductive and respiratory syndrome virus between NADC30-like and a MLV-like: genetic characterization and pathogenicity for piglets. Infect Genet Evol. 2017;54:279-86.

50. Liu J, Zhou X, Zhai J, Li B, Wei C, Dai A, Yang X, Luo M. Genetic diversity and evolutionary characteristics of type 2 porcine reproductive and respiratory syndrome virus in southeastern China from 2009 to 2014. Arch Virol. 2017;162:2603-15.

51. Liu J, Zhou X, Zhai J, Wei C, Dai A, Yang X, Luo M. Recombination in JXA1-R vaccine and NADC30-like strain of porcine reproductive and respiratory syndrome viruses. Vet Microbiol. 2017;204:110-20.

52. Li Y, Ji G, Wang J, Tan F, Zhuang J, Li X, Tian K. Complete genome sequence of an NADC30-like porcine reproductive and respiratory syndrome virus characterized by recombination with other strains. Genome Announc. 2016;4

53. Shi M, Holmes EC, Brar MS, Leung FCC, Recombination I. Associated with an outbreak of novel highly pathogenic porcine reproductive and respiratory syndrome viruses in China. J Virol. 2013;87:10904-7.
54. Wenhui L, Zhongyan W, Guanqun Z, Zhili L, Jing Yun M, Qingmei X, Baoli S, Yingzuo $B$. Complete genome sequence of a novel variant porcine reproductive and respiratory syndrome virus (PRRSV) strain: evidence for recombination between vaccine and wild-type PRRSV strains. J Virol. 2012;86:9543.

55. Sun Z, Wang J, Bai X, Ji G, Yan H, Li Y, Wang Y, Tan F, Xiao Y, Li X, Tian K. Pathogenicity comparison between highly pathogenic and NADC30-like porcine reproductive and respiratory syndrome virus. Arch Virol. 2016; 161:2257-61.

56. Zhou Z, Liu Q, Hu D, Zhang Q, Han T, Ma Y, Gu X, Zhai X, Tian K. Complete genomic characterization and genetic diversity of four European genotype porcine reproductive and respiratory syndrome virus isolates from China in 2011. Virus Genes. 2015;51:375-84.

57. Liu J, Wei C, Dai A, Fan K, Yang B, Huang C, Li X, Yang X, Luo M. Complete genomic characterization of two European-genotype porcine reproductive and respiratory syndrome virus isolates in Fujian province of China. Arch Virol. 2017;162:823-33.

58. Wang X, Yang X, Zhou R, Zhou L, Ge X, Guo X, Yang H. Genomic characterization and pathogenicity of a strain of type 1 porcine reproductive and respiratory syndrome virus. Virus Res. 2016;225:40-9.

59. Stadejek T, Oleksiewicz MB, Scherbakov AV, Timina AM, Krabbe JS, Chabros K, Potapchuk D. Definition of subtypes in the European genotype of porcine reproductive and respiratory syndrome virus: nucleocapsid characteristics and geographical distribution in Europe. Arch Virol. 2008;153:1479-88.

60. Stadejek T, Stankevicius A, Storgaard T, Oleksiewicz MB, Belak S, Drew TW, Pejsak Z. Identification of radically different variants of porcine reproductive and respiratory syndrome virus in Eastern Europe: towards a common ancestor for European and American viruses. J Gen Virol. 2002;83:1861-73.

61. Stadejek T, Oleksiewicz MB, Potapchuk D, Podgorska K. Porcine reproductive and respiratory syndrome virus strains of exceptional diversity in eastern Europe support the definition of new genetic subtypes. J Gen Virol. 2006;87:1835-41.

62. Stadejek T, Stankevicius A, Murtaugh MP, Oleksiewicz MB. Molecular evolution of PRRSV in Europe: current state of play. Vet Microbiol. 2013;165:21-8.

63. Ming S, Yongying M, Bohua L, Huiying L, Xiaoyu D, Qiaorong L, Mingming Q, Xi C, Xinyan Y, Xizhao C. Pathogenic characterization of European genotype porcine reproductive and respiratory syndrome virus recently isolated in mainland China. Open Virol J. 2017;11:83-9.

64. Chen N, Liu Q, Qiao M, Deng X, Chen X, Sun M. Whole genome characterization of a novel porcine reproductive and respiratory syndrome virus 1 isolate: genetic evidence for recombination between Amervac vaccine and circulating strains in mainland China. Infect Genet Evol. 2017:54:308-13.

65. Bonckaert C, van der Meulen K, Rodríguez-Ballarà I, Pedrazuela Sanz R, Martinez MF, Nauwynck HJ. Modified-live PRRSV subtype 1 vaccine UNISTRAIN $^{\circledR}$ PRRS provides a partial clinical and virological protection upon challenge with east European subtype 3 PRRSV strain Lena. Porcine Health Manag. 2016;2

66. Wang G, Yu Y, Zhang C, Tu Y, Tong J, Liu Y, Chang Y, Jiang C, Wang S, Zhou EM, Cai $X$. Immune responses to modified live virus vaccines developed from classical or highly pathogenic PRRSV following challenge with a highly pathogenic PRRSV strain. Dev Comp Immunol. 2016:62:1-7.

67. Wei Z, Zhang J, Zhuang J, Sun Z, Gao F, Yuan S. Immunization of pigs with a type 2 modified live PRRSV vaccine prevents the development of a deadly long lasting hyperpyrexia in a challenge study with highly pathogenic PRRSV JX143. Vaccine. 2013;31:2062-6.

68. Zhou L, Yang B, Xu L, Jin H, Ge X, Guo X, Han J, Yang H. Efficacy evaluation of three modified-live virus vaccines against a strain of porcine reproductive and respiratory syndrome virus NADC30-like. Vet Microbiol. 2017;207:108-16.

69. Bai X, Wang Y, Xu X, Sun Z, Xiao Y, Ji G, Li Y, Tan F, Li X, Tian K. Commercial vaccines provide limited protection to NADC30-like PRRSV infection. Vaccine. 2016;34:5540-5.

70. Mengeling WL, Vorwald AC, Lager KM, Clouser DF, Wesley RD. Identification and clinical assessment of suspected vaccine-related field strains of porcine reproductive and respiratory syndrome virus. Am J Vet Res. 1999;60:334-40.

71. Nielsen TL, Nielsen J, Have P, Baekbo P, Hoff-Jorgensen R, Botner A. Examination of virus shedding in semen from vaccinated and from previously infected boars after experimental challenge with porcine reproductive and respiratory syndrome virus. Vet Microbiol. 1997;54:101-12.

72. Zhou L, Yang X, Tian Y, Yin S, Geng G, Ge X, Guo X, Yang H. Genetic diversity analysis of genotype 2 porcine reproductive and respiratory syndrome viruses emerging in recent years in China. Biomed Res Int. 2014;2014:1-13. 
73. Jiang Y, Xia T, Zhou Y, Yu L, Yang S, Huang Q, Li L, Gao F, Qu Z, Tong W, Tong $\mathrm{G}$. Characterization of three porcine reproductive and respiratory syndrome virus isolates from a single swine farm bearing strong homology to a vaccine strain. Vet Microbiol. 2015;179:242-9.

74. Zhao H, Han Q, Zhang L, Zhang Z, Wu Y, Shen H, Jiang P. Emergence of mosaic recombinant strains potentially associated with vaccine JXA1-R and predominant circulating strains of porcine reproductive and respiratory syndrome virus in different provinces of China. Virol J. 2017;14

75. Corzo CA, Mondaca E, Wayne S, Torremorell M, Dee S, Davies P, Morrison RB. Control and elimination of porcine reproductive and respiratory syndrome virus. Virus Res. 2010;154:185-92.

76. Rathkjen PH, Dall J. Control and eradication of porcine reproductive and respiratory syndrome virus type 2 using a modified-live type 2 vaccine in combination with a load, close, homogenise model: an area elimination study. Acta Vet Scand. 2017;59:4.

77. Murtaugh MP, Genzow M. Immunological solutions for treatment and prevention of porcine reproductive and respiratory syndrome (PRRS). Vaccine. 2011;29:8192-204.

78. Linhares DC, Johnson C, Morrison RB. Correction: economic analysis of vaccination strategies for PRRS control. PLoS One. 2016;11:e150444.

79. Zhang L, Feng Y, Martin DP, Chen J, Ma S, Xia P, Zhang G. Genetic diversity and phylogenetic analysis of the ORF5 gene of PRRSV from central China. Res Vet Sci. 2017;115:226-34.

80. Zhang Q, Xu X, You S, Li Y, Wang H, Bai J, Jiang P. Emerging of two new subgenotypes of porcine reproductive and respiratory syndrome viruses in Southeast China. Microb Pathog. 2016;97:27-33.

81. Tian K. NADC30-Like Porcine Reproductive and Respiratory Syndrome in China. The Open Virology Journal. 2017;11:59-65.

82. Dong J, Wang Y, Yu L, Zhang P, Liu X, Zhang L, Liu Y, Liang P, Wang L, Song C. Pathogenicity of a newly emerged recombined porcine reproductive and respiratory syndrome virus strain (subgenotype III) in China. Vet Microbiol. 2017;210:162-6.

\section{Submit your next manuscript to BioMed Central and we will help you at every step:}

- We accept pre-submission inquiries

- Our selector tool helps you to find the most relevant journal

- We provide round the clock customer support

- Convenient online submission

- Thorough peer review

- Inclusion in PubMed and all major indexing services

- Maximum visibility for your research

Submit your manuscript at www.biomedcentral.com/submit 